\title{
Bipedicled Mini V-Y Advancement Flap for Skin Defect of the Face
}

\section{Mikiko Ooshima, Mariko Kochi, Daichi Morioka*, Towa Miyamoto, Tomoko Tsuda, Koichi Kadomatsu}

Department of Plastic and Reconstructive Surgery, Showa University, Tokyo, Japan

Email: ^dmorioka@gmail.com

How to cite this paper: Ooshima, M., Kochi, M., Morioka, D., Miyamoto, T., Tsuda, T. and Kadomatsu, K. (2018) Bipedicled Mini V-Y Advancement Flap for Skin Defect of the Face. Modern Plastic Surgery, 8, 15-20.

https://doi.org/10.4236/mps.2018.82003

Received: January 11, 2018

Accepted: April 5, 2018

Published: April 8, 2018

Copyright $\odot 2018$ by authors and Scientific Research Publishing Inc. This work is licensed under the Creative Commons Attribution International License (CC BY 4.0).

http://creativecommons.org/licenses/by/4.0/

\begin{abstract}
In young patients, even small circular facial defects after the excision of benign skin tumors present a reconstructive challenge. The usefulness of a $\mathrm{V}-\mathrm{Y}$ advancement flap for reconstructing such defects is well documented. We refined this technique as a mini V-Y advancement flap consisting of two subcutaneous pedicles that vascularize the skin island via subdermal plexus lateral bridges. This technique was used for 21 middle-aged or younger patients with a small benign skin lesion. None of them experienced any postoperative complications. Aesthetically excellent results were found in all patients. This small advancement flap could be attempted as an alternative to fusiform excision of small skin lesions, particularly in younger patients.
\end{abstract}

\section{Keywords}

Facial Skin Tumor, Skin Defect, Advancement Flap, Subdermal Plexus

\section{Introduction}

Excision of facial skin tumors frequently leaves circular defects. These are primarily closed using dog-ear resection and direct approximation, resulting theoretically in scars up to three or even four times the length of the original lesion. In elderly patients, even long scars along relaxed skin tension lines can be masked by wrinkles, and such a fusiform excision would produce aesthetically good results in the region of the eyelid, forehead, and cheeks.

In middle-aged or younger patients, however, circular defects of the face after benign skin tumor excision represent a reconstructive challenge, even if the defects are small. Conspicuous scars on the face may have a significant impact on the quality of life of the patient [1]. Several local flaps including M-plasty, transposition, and rotation have been attempted to minimize scar length, unfa- 
vorable deformity, and facial asymmetry [2] [3].

Among different local flap varieties, the V-Y advancement flap is versatile and aesthetically superior to other options especially in the nasal and paranasal regions, because intact skin sacrifice and contour irregularity are minimal [4]. However, the length of this conventional V-shaped flap is two or more times longer than the diameter of the skin defect [5].

Earlier, for small facial defects, we have applied a conventional (subcutaneous-pedicled) but small V-Y advancement flap by using a triangular skin that would be removed as a "dog ear". While most such flap operations were successful, some lead to flap necrosis owing to poor blood supply to the pedicle. Having refined the pedicle of this mini triangular flap, we here describe a horizontally bipedicled V-Y advancement flap.

\section{Operative Technique}

Middle-aged or younger patients with a small (approximately $\leq 10 \mathrm{~mm}$ in diameter) benign skin lesion underwent reconstruction of a circular or near-circular defect by using the bipedicled mini V-Y advancement flap.

The principle of the technique is to preserve a triangular skin that is supposed to be sacrificed when a circular skin defect is primarily closed, and to use it as a local flap. Unlike the conventional V-Y advancement flap, the skin island is vascularized via subdermal plexus lateral bridges of the two subcutaneous pedicles (Figure 1). This concept of a horizontally bipedicled V-Y advancement flap has been reported by Pontes et al. [6].

Following the excision of the skin tumor, a small V-shaped flap is designed in reference to naturally existing contour lines or aesthetic units. As this is coincident to one of the two skin pieces removed as dog ears, the length of this newly created flap should be either equal to or lesser than the diameter of the defect (Figure 2).

The dermis alongside the $\mathrm{V}$-shaped flap is undermined on both sides at a level between the dermis and subdermis so that the underlying subdermal plexus is not damaged. This superficial undermining is performed from the edge of the defect (corners of the top of the V) and extended up to the tail of the flap. An excessively wide dissection of the superficial layer of the pedicles is to be avoided to

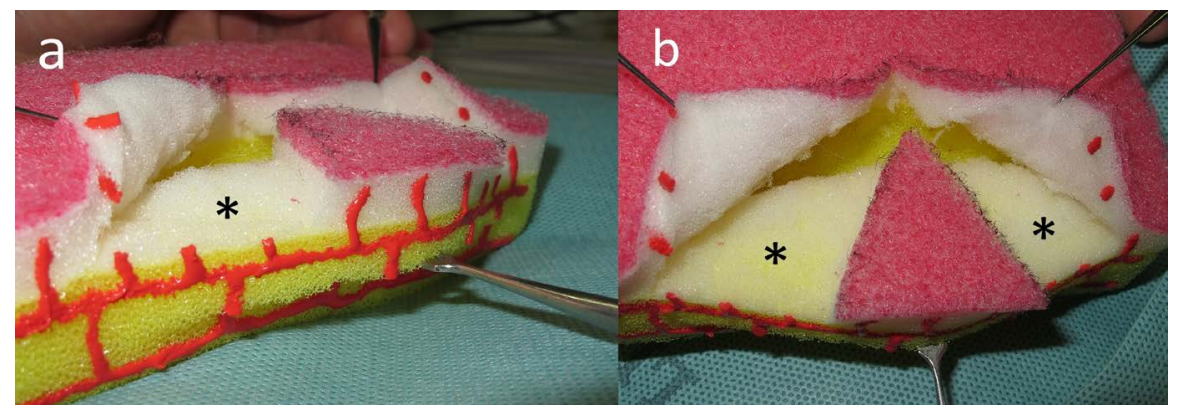

Figure 1. A sponge model of bipedicled V-Y advancement (a). The skin island is vascularized via subdermal plexus bridges $\left(^{*}\right)$. This flap can move horizontally (b). 


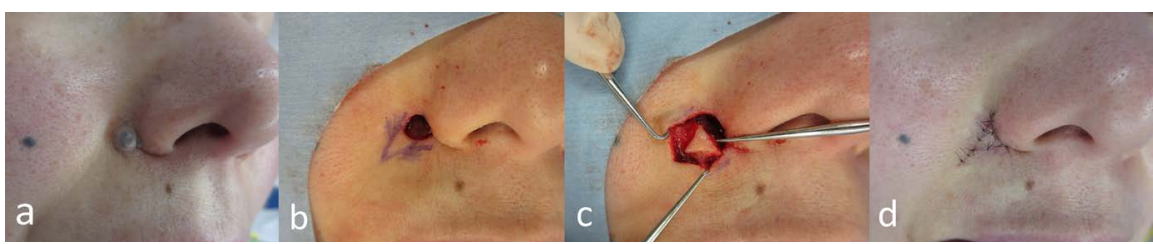

Figure 2. Operative technique for the bipedicled mini V-Y advancement flap.

prevent ischemia, hypertrophic scar, or hyperpigmentation of the overlaying skin.

Likewise, the deep layer of the pedicle is undermined from the top of the $\mathrm{V}$ extending to the tail of the flap and the end of the bilateral pedicles. This dissection must be deep enough to include the subdermal plexus into the pedicle. The depth of undermining should be considered depending on the operation site. For example, in the cheek, this is carried out at the level of the intermediate layer of the subcutaneous fat tissue region: in the glabellar, nasal, and paranasal regions, just above the muscles. When the tail of the flap is freed along with the far end of the pedicles, the flap can be advanced over the defect horizontally, similar to when a bow gun is triggered off.

The defect and flap are closed using 6-0 or 7-0 nylon sutures following several intradermal key sutures. Dense sutures with large bites causing flap necrosis should be avoided. Half-buried horizontal mattress sutures may be used for the flap corners. The sutures are removed 7 to 10 days after the surgery.

\section{Results}

During the last 2 years, the described flap was used in 21 patients, aged between 9 and 58 years, with a small benign facial skin tumor (Table 1). The benign tumors included 16 nevi, 2 mixed tumors, and 3 other lesions. All reconstructions were performed by a single surgeon (D.M.). Except for one child who underwent the reconstruction under general anesthesia (Case 1, Table 1), all patients had the reconstruction under local anesthesia (1\% lidocaine with 1:100,000 epinephrine) in outpatient settings.

All patients showed an uneventful postoperative course. None of them presented with any early complications including hematoma, flap necrosis, infection, and wound dehiscence, or long-term sequelae including trap-door deformity, hypertrophic scar, and hyperpigmentation during their 6-month to 2-year follow-up. Aesthetically excellent results were achieved in all patients (Figure 3).

\section{Discussion}

The usefulness of the V-Y advancement flap for reconstruction of facial skin defects has been well documented [1] [4] [5]. Andrades et al. [7] analyzed the geometry of a conventional V-Y flap that is advanced along two planes: vertical and horizontal (Figure 4). As the pivot point is located at the deepest level along the vertical plane, this point must be deeper to gain more advancement. Otherwise, the flap can be advanced depending on how much the pedicle is freed 
Table 1. Characteristics of patients.

\begin{tabular}{|c|c|c|c|c|c|}
\hline $\begin{array}{c}\text { Case } \\
\text { number }\end{array}$ & $\begin{array}{c}\text { Age (years), } \\
\text { sex }\end{array}$ & Diagnosis of lesion & Location & $\begin{array}{l}\text { Defect size } \\
\quad(\mathrm{mm})\end{array}$ & $\begin{array}{l}\text { Flap length } \\
(\mathrm{mm})\end{array}$ \\
\hline 1 & $9, \mathrm{M}$ & $\mathrm{NCN}$ & Nostril sill & $10 \times 8$ & 9 \\
\hline 2 & $10, \mathrm{~F}$ & $\mathrm{NCN}$ & Nasal dorsum & $11 \times 10$ & 10 \\
\hline 3 & $14, \mathrm{~F}$ & Sebaceous nevus & Cheek & $10 \times 8$ & 9 \\
\hline 4 & $12, \mathrm{M}$ & $\mathrm{NCN}$ & Cheek & $9 \times 9$ & 8 \\
\hline 5 & $19, \mathrm{~F}$ & $\mathrm{NCN}$ & Chin & $8 \times 9$ & 8 \\
\hline 6 & $20, \mathrm{M}$ & Hypertrophic scar & Cheek & $8 \times 8$ & 8 \\
\hline 7 & $23, \mathrm{~F}$ & Blue nevus & Chin & $8 \times 8$ & 8 \\
\hline 8 & $24, \mathrm{~F}$ & $\mathrm{NCN}$ & Paranasal region & $7 \times 7$ & 6 \\
\hline 9 & $28, \mathrm{~F}$ & Blue nevus & Cheek & $7 \times 7$ & 6 \\
\hline 10 & $28, \mathrm{M}$ & $\mathrm{NCN}$ & Paranasal region & $5 \times 5$ & 4 \\
\hline 11 & $30, \mathrm{~F}$ & Mixed tumor & Nasal dorsum & $9 \times 9$ & 8 \\
\hline 12 & $34, \mathrm{M}$ & $\mathrm{NCN}$ & Glabella & $7 \times 7$ & 5 \\
\hline 13 & $37, \mathrm{~F}$ & $\mathrm{NCN}$ & Paranasal & $7 \times 7$ & 7 \\
\hline 14 & $37, \mathrm{M}$ & Mixed tumor & Forehead & $9 \times 9$ & 7 \\
\hline 15 & $40, \mathrm{M}$ & $\mathrm{NCN}$ & Cheek & $12 \times 10$ & 10 \\
\hline 16 & $45, \mathrm{~F}$ & Fibrous papule & Ala & $6 \times 5$ & 6 \\
\hline 17 & $47, \mathrm{~F}$ & $\mathrm{NCN}$ & $\begin{array}{l}\text { Nasolabial } \\
\text { region }\end{array}$ & $10 \times 11$ & 8 \\
\hline 18 & $53, \mathrm{M}$ & Trichoepithelioma & Nasal dorsum & $10 \times 10$ & 9 \\
\hline 19 & $55, \mathrm{~F}$ & $\mathrm{NCN}$ & Alar base & $8 \times 8$ & 8 \\
\hline 20 & $58, \mathrm{~F}$ & $\mathrm{NCN}$ & Alar base & $8 \times 8$ & 7 \\
\hline 21 & $58, \mathrm{M}$ & $\mathrm{NCN}$ & Glabella & $10 \times 10$ & 9 \\
\hline
\end{tabular}

Abbreviations: F, female; M, male; NCN, nevocellular nevus.

horizontally. Given this fact, advancement and mobilization for closure with tension may lead to flap necrosis especially in small flaps [5]. However, because the horizontally (subdermal plexus-based) bipedicled V-Y advancement flap moves only horizontally and is provided with stable blood supply, we believe that this procedure is superior to conventional, vertically (perforating vessel-based) pedicled V-Y advancement.

The described flap is recommended especially for small skin defects in young to middle-aged patients. Although it could, of course, be used for facial skin defects of elderly patients, such small defects can be closed as a conventional fusiform excision in most cases. Our modified technique is thus not highly indicated in this group.

One concern about the described flap is that bleeding from the pedicles often interferes with accurate undermining. However, thorough cauterization for bleeding should be avoided, as it may lead to flap ischemia. Injection of relatively excessive amounts of local anesthetics (tumescent technique) minimizes the 

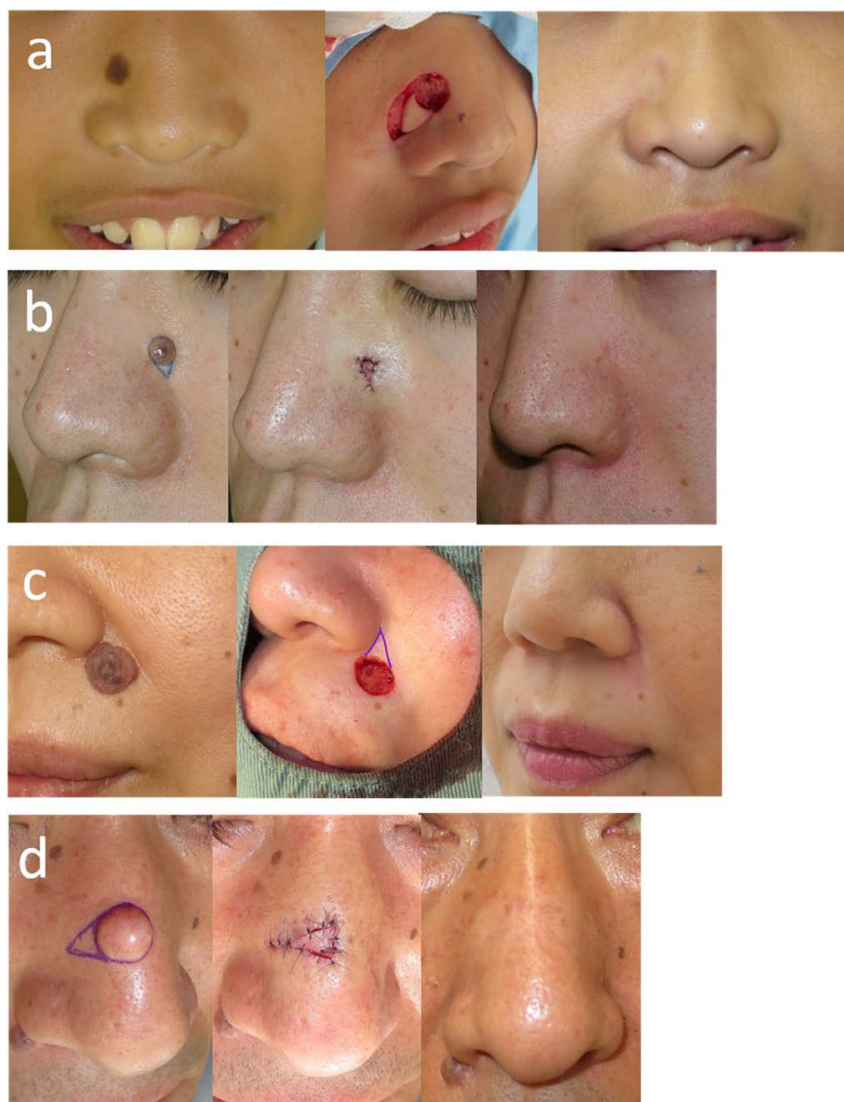

Figure 3. Photographic examples of preoperative (left image), intraoperative (center image), and postoperative (right image) cases. (a) Case 2. (b) Case 10. (c) Case 17. (d) Case 18.

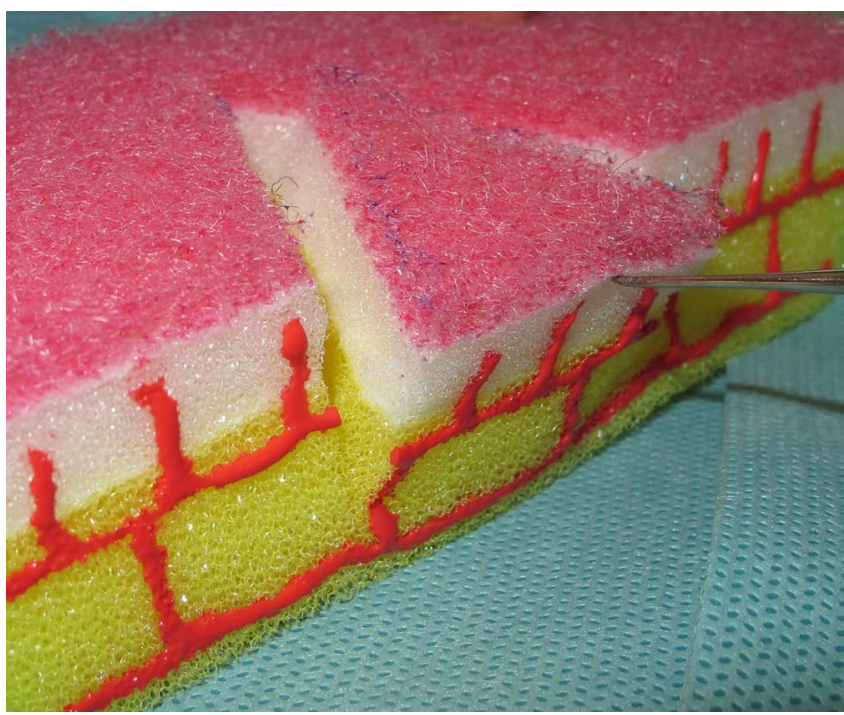

Figure 4. A sponge model of conventional V-Y advancement flap nosediving. The skin island is vascularized via perforating vessels. Unlike the bipedicled V-Y flap, this is advanced along two planes: vertical and horizontal. To gain greater advancement, the pivot point should be deeper, or the pedicle should be freed more in the horizontal plane. 
need for electrocautery, and enables easy flap elevation. Thus, even for operations under general anesthesia, local injection of 1:1,000,000 epinephrine is recommended.

Alopecia on the bipedicled flap is another concern when this flap is designed in hairy skin. As superficial undermining of the pedicle damages the hair follicles of the flap and the surrounding skin, this technique is best avoided on the cheeks and chin of male patients.

\section{Conclusion}

In conclusion, although the indication of the bipedicled mini V-Y advancement flap is relatively limited, it is a welcome addition to the armamentarium of surgeons. This technique might be considered an alternative to simple fusiform excision of small facial skin lesion especially in middle-aged or younger patients. If, during the operation, the surgeon finds that the flap is unsuccessful, the procedure can be converted into a conventional fusiform excision.

\section{Declaration of Conflicting Interests}

The authors declared no potential conflicts of interest with respect to the research, authorship, and/or publication of this article.

\section{Funding}

The authors received no financial support for the research, authorship, and/or publication of this article.

\section{References}

[1] Pepper, J.P. and Baker, S.R. (2013) Local Flaps: Cheek and Lip Reconstruction. JAMA Facial Plastics Surgery, 15, 374-382. https://doi.org/10.1001/jamafacial.2013.1608

[2] Henke, C.W. (1987) Repair of Surgical Defects. Dermatologic Clinics, 5, 287-302.

[3] Chu, E.A. and Byrne, P.J. (2009) Local Flaps I: Bilobed, Rhombic, and Cervicofacial. Facial Plastic Surgery Clinics of North America, 17, 349-360. https://doi.org/10.1016/j.fsc.2009.05.003

[4] Kalus, R. and Zamora, S. (1996) Aesthetic Considerations in Facial Reconstructive Surgery: The V-Y Flap Revisited. Aesthetic Plastic Surgery, 20, 83-86. https://doi.org/10.1007/BF02275583

[5] Zook, E.G., Van Beek, A.L., Russel, R.C. and Moore, J.B. (1980) V-Y Advancement Flap for Facial Defects. Plastic and Reconstructive Surgery, 65, 786-797. https://doi.org/10.1097/00006534-198006000-00011

[6] Pontes, L., Ribeiro, M., Vrancks, J.J. and Guimarães, J. (2002) The New Bilaterally Pedicled V-Y Advancement Flap for Face Reconstruction. Plastic and Reconstructive Surgery, 109, 1870-1874. https://doi.org/10.1097/00006534-200205000-00013

[7] Andrades, P.R., Calderon, W., Leniz, P., Bartel, G., Danilla, S. and Benitez, S. (2005) Geometric Analysis of the V-Y Advancement Flap and Its Clinical Applications. Plastic and Reconstructive Surgery, 115, 1582-1590. https://doi.org/10.1097/01.PRS.0000160693.82527.D4 